Tropical Journal of Pharmaceutical Research April 2013; 12 (2): 247-253

ISSN: $1596-5996$ (print); 1596-9827 (electronic)

(C) Pharmacotherapy Group, Faculty of Pharmacy, University of Benin, Benin City, 300001 Nigeria.

All rights reserved.

Available online at http://www.tjpr.org

Original Research Article

http://dx.doi.org/10.4314/tjpr.v12i2.18

\title{
Effect of Divergence in Patients' Socioeconomic Background on their Perspective of the Role of the Community Pharmacist in Amman, Jordan
}

\author{
Eyad Qunaibi ${ }^{{ }^{*}}$, Iman A Basheti ${ }^{1}$, Salim A Hamadi ${ }^{2}$, Nailya R Bulatova ${ }^{3}$, Adam \\ Shanah $^{1}$ and Eman Abu-Gharbieh ${ }^{4}$ \\ ${ }^{1}$ Faculty of Pharmacy, Applied Sciences University, Amman, ${ }^{2}$ Department of Pharmacology \& Biomedical Sciences, Faculty of \\ Pharmacy and Medical Sciences, Petra University, ${ }^{3}$ Department of Biopharmaceutics \& Clinical Pharmacy, Faculty of \\ Pharmacy, The University of Jordan, Amman, Jordan, ${ }^{4}$ Dubai Pharmacy College, Dubai, UAE.
}

*For correspondence: E-mail: yequnaibi@asu.edu.jo, eyadqunaibi@yahoo.com

\begin{abstract}
Purpose: To examine the effect of divergence in patients' socioeconomic background on their perspective of the roles of the pharmacist in Amman, Jordan.

Methods: This was a single-phase observational study conducted in two different socioeconomic areas: Western (WA) and Eastern Amman (EA, which is of a lower socioeconomic status than WA) in March to May of both 2009 and 2010. A validated questionnaire was completed by patients walking into community pharmacies. The source of advice (clinical specialist, general practitioner, pharmacist, nurse or herbalist) regarding patient's disease management and medication use, as well as patients' expectation of the pharmacist were investigated.

Results: 2000 patients (mean age: $35.1 \pm 13.7$ years, $57.2 \%$ males) visiting community pharmacies in Amman (1000 each from WA and EA) took part in the study. The majority of patients chose the pharmacist as the source of advice on medication use (WA, $50.8 \%$; EA, $53.6 \%$ ), followed by the clinical specialist (WA, $35.7 \%$ vs EA, $26.9 \%, p=0.001)$. Other aspects of patient perspective and expectation of the pharmacist were also assessed; in several instances, more reliance on the pharmacist was observed in EA (lower socioeconomic status) than in WA.

Conclusion: The findings of this study is important for future social pharmacy studies in the area, as it shows that socioeconomic status influences patient's perception of the role of the community pharmacist in Amman, Jordan.
\end{abstract}

Keywords: Socioeconomic status, Community pharmacist, Jordan, Patient perception, Counseling

Tropical Journal of Pharmaceutical Research is indexed by Science Citation Index (SciSearch), Scopus, International Pharmaceutical Abstract, Chemical Abstracts, Embase, Index Copernicus, EBSCO, African Index Medicus, JournalSeek, Journal Citation Reports/Science Edition, Directory of Open Access Journals (DOAJ), African Journal Online, Bioline International, Open-J-Gate and Pharmacy Abstracts

\section{INTRODUCTION}

In recent years, the pharmacy profession is increasingly recognized as an important partner in the multidisciplinary health care in Jordan. Pharmaceutical care requires the pharmacist to be more accountable in ensuring that a patient achieves positive outcomes from therapy [1-4].
The patient's perception of the pharmacist's role relative to the roles of other health care professionals (HCPs) is likely to be influenced by many factors such as patient's socioeconomic status [5]. This is because the pharmacist is probably the only HCP that is approached for regular counseling without the requirement of a consultation fee. Yet, to the best of our knowledge, no previous study has been 
conducted to examine the effect of socioeconomic status on patient perception of HCPs in Jordan, a country with divergence in the socioeconomic status of its inhabitants.

Jordan has more than 2000 functioning community pharmacies distributed throughout the country. Amman, the capital, has $60 \%$ of those pharmacies (1203). Amman is divided into two major areas - Western Amman (WA) which is relatively developed, and Eastern Amman (EA) which is a lower income, poverty-striken area. Therefore, comparing patient perceptions in these two areas serves two main aims. First, it will enable better understanding of patients' expectation of the services that can be delivered by a community pharmacist and his role relative to otherHCPs in Amman, Jordan. Second, it would provide some insight into the influence of socioeconomic divergence on patient's perspective of the pharmacist's role in healthcare.

\section{METHODS}

The study was undertaken over a period of 4 months (March to May of both 2009 and 2010) in randomly selected community pharmacies in WA and EA, Jordan. All of the pharmacy students enrolled in the Clinical Pharmacy and Therapeutics 1 and 2 course units at the Applied Science University for the year 2009/2010 ( $n=$ 143) assisted in carrying out this study.

Each student approached 10 to 15 patients walking into a community pharmacy to purchase prescription medications. The pharmacies were randomly selected from WA and EA. The consent of the pharmacist in charge of the pharmacy was obtained before patients were approached. Patients that agreed to take part in the study provided informed oral consent.

The pharmacy students were trained to carry out the assignment including on the issue of cognitive bias that can lead to social desirability (having respondents answering questions in a way that is not completely according to their true beliefs). Importance of preventing this bias with practical measures to attain true results were clarified and implemented. The pharmacy students introduced themselves as researchers, pharmacist in charge not being present during the questionnaire completion; questionnaire was completed outside the community pharmacy; and completed questionnaires were inserted in envelopes and sealed by the pharmacy students. Following questionnaire completion, the sealed envelopes were stamped by the pharmacist in charge, and returned to the principal researchers $(E Q, I B$, and NB). The principal researchers contacted a random sample of the pharmacies to verify that the study was carried out according to protocol.

To avoid respondents confusing who is a pharmacist and pharmacy assistant, it was pointed out to them who the pharmacist was when completing the questionnaire. The questionnaire included both closed and open questions prepared by the principal researchers, and was in two parts, Part A investigated source of advice regarding the patient's medication use, review of treatment for chronic conditions, and non-pharmacological measures, in addition to the most trusted HCPs in terms of advice on medical condition. Part B investigated specifically what is expected of the community pharmacist by the patient, such as time and extent of counseling, provision of counseling areas, home delivery of medications and handling of extra paid services such as the Medication Management Review (MMR) service.

To ensure face validity, the questionnaire (in both English and Arabic languages) was evaluated by three academics (EQ, IB, NB) who have previous experience in conducting clinical studies and have a wide range of clinical professional experience. The questionnaire was then completed by pharmacy students $(n=15)$ to test for clarity of questions. Views and comments of the students were considered by the researchers and then incorporated where appropriate into the final version of the questionnaire. To assess testretest reliability, the questionnaire was administered on two occasions to 15 randomly selected pharmacy students and 15 community pharmacy customers. The second testing took place two weeks after the first one, and was not included in the final survey analysis. Test-retest reliability was computed using Spearman's correlation coefficient (r). The rho-value was 0.84, which implies acceptable test-retest reliability.

Respondents were asked to answer the first part of the questionnaire using the options 'general practitioner', 'clinical specialist', 'pharmacist', 'nurse' and 'others'. The second part of the questionnaire had the options 'yes', 'no', or 'not sure'. There was a section inviting comments at the end of the questionnaire.

\section{Data analysis}

Participants' responses were encoded and the data were analyzed using Statistical Package for the Social Sciences (SPSS, version 17, Chicago, IL, US). Descriptive analysis was carried out to determine the proportion of patients who 
selected each of theHCPs for the first part of the questionnaire, and proportion of patients who agreed or disagreed with each of the questions in the second part of the questionnaire. Chi square test was used to identify any significant difference among the participants' responses for WA and EA, with significance defined as $p \leq$ 0.05 .

Sample size calculation was based on the population of Amman (1,206,266 in the year 2010) [6] minimum sample size of 443 was calculated, for a margin error of $5 \%$, confidence level of $95 \%$, a response distribution of $50 \%$, and an added on $15 \%$, since a non-parametric test was planned to be used in the analysis. We decided to collect a sample size of 2000 patients (1000 patients for each region), which meets the required minimum sample size, and gives each student the chance to meet and talk to at least 10 patients.

\section{RESULTS}

Two thousand patients visiting community pharmacies in Amman, Jordan were approached by 143 advanced pharmacy students. Fifty seven percent of the patients interviewed were males (no significant difference between WA and EA, $p$ $=0.179$ ). Mean age of patients was $35.2 \pm 13.7$ (no significant difference between WA and EA, $p$ $=0.283$ ). A majority of patients interviewed were university students and housewives (Table 1).

Half of the WA (50.8\%) and EA (53.6\%) patients believed that community pharmacists were the HCP that provide them with advice most frequently on their medication use, including medical devices, such as asthma inhalers, followed by clinical specialists (Figure $1 A$ and $B$ ). The proportion of $E A$ patients that chose pharmacist over clinical specialist was significantly higher than that of WA patients ( $p=$ 0.001).
In addition, we found that a majority of the patients tend to go back to their specialists for regular review of treatment for their chronic conditions (Figure 2A and $\mathrm{B}$ ). The pharmacists came next in both areas of Amman, with more patients doing so than to GPs. The proportion of WA patients that chose specialists for treatment review over the pharmacist was significantly higher than for EA patients $(p<0.001)$.

When it comes to patients' trust in theHCPs, specialists were the most trusted by a majority of patients requesting advice on their medical conditions (WA $66.8 \%$ vs EA $54.0 \%, p<0.001$ ), followed by the GP (WA $14.6 \%$ vs EA $21.4 \%$ ), and the pharmacist (WA $13.6 \%$ vs EA $18.1 \%$ ), with no significant difference between the GP and pharmacist $(p=0.536)$.

With regard to the use of non-pharmacological treatments (alternative medicine and complimentary medicine), the HCPs that discussed this form of treatment most with patients were the 'traditional naturopath' (WA $32.5 \%$ vs EA $36.1 \%$ ) and pharmacist (WA 31.9 $\%$ vs. EA $33.6 \%$ ), with no significant difference between these two HCPs across WA and EA ( $p$ $=0.716)$. Non-pharmacological treatments were used by almost half of the patients (47.5\%). Reported non-pharmacological treatments include natural treatments for diabetes, hypertension, fungal infections, gastrointestinal spasms, flu, and body weight reduction. Many patients $(77.0 \%)$ believed that complimentary treatments were a safer alternative to drugs and have less side effects. A majority of patients from WA $(70.7 \%)$ and EA $(64.2 \%)$ had tried herbal and complementary treatments $(p<0.001)$. Only a few patients did not believe in this type of therapy (WA $0.2 \%$ vs EA $1.0 \%$ ). Categorization of the herbal treatments that were mentioned the most by patients indicates that they include ginger to treat loss of voice, herbal volatile oil for gastrointestinal spasm, hot extract of parsley for kidney stones, and various herbal medicines for enhancement of memory.

Table 1: Demographic characteristics of patients in the Western $(n=1000)$ and Eastern $(n=1000)$ Amman areas

\begin{tabular}{ccccc}
\hline Characteristic & $\begin{array}{c}\text { Western \& Eastern } \\
\text { Amman }\end{array}$ & Western Amman & Eastern Amman & $\begin{array}{c}\boldsymbol{P} \text {-value (Chi } \\
\text { square test) }\end{array}$ \\
\hline Age (mean \pm SD) & $35.13 \pm 13.73$ & $34.57 \pm 13.72$ & $35.65 \pm 13.73$ & 0.283 \\
Gender (male:female) & $1096: 821$ & $512: 409$ & $584: 412$ & 0.179 \\
Occupation n (\%) & & & & 0.089 \\
$-\quad$ Student & $449(24.4)$ & $233(26.5)$ & $216(22.4)$ & $143(14.8)$ \\
$-\quad$ Housewife & $281(15.3)$ & $138(15.7)$ & $82(8.5)$ & \\
$-\quad$ Academic & $135(7.3)$ & $53(6.0)$ & $75(7.8)$ & \\
$-\quad$ Engineer & $163(8.8)$ & $88(10.0)$ & $24(2.5)$ & \\
$-\quad$ Doctor & $50(2.7)$ & $26(3.0)$ & \\
\hline
\end{tabular}




\section{Qunaibi et al}

A

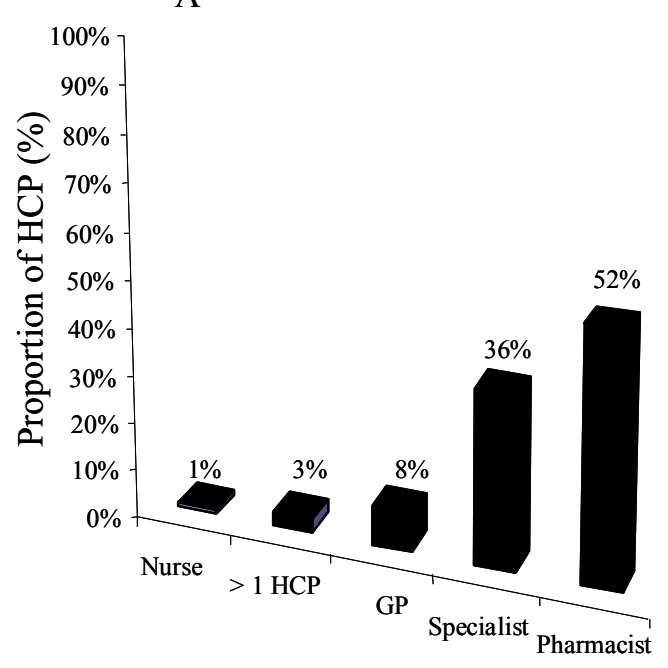

B

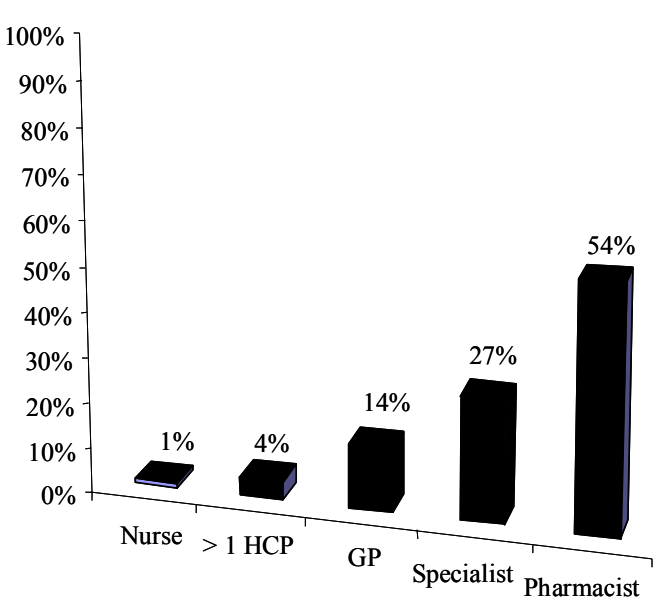

Type of health care professional

$\mathrm{GP}=$ General Practitioner

Specialist $=$ a specialist in any clinical area

$>1 \mathrm{HCP}=$ More than one health care professional

Figure 1: Proportion of health care professionals that provided advice most on medication use; $\mathbf{A}=$ Western Amman $(n=1000)$, and $B=$ Eastern Amman $(n=1000)$

A

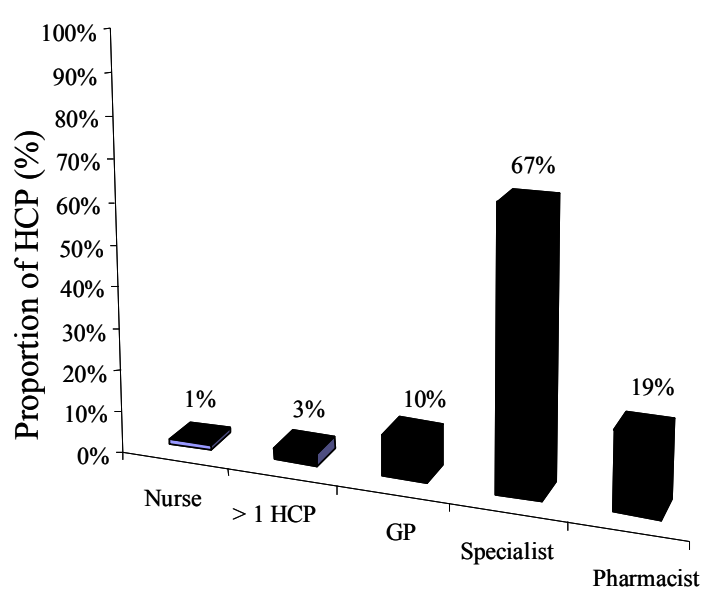

B

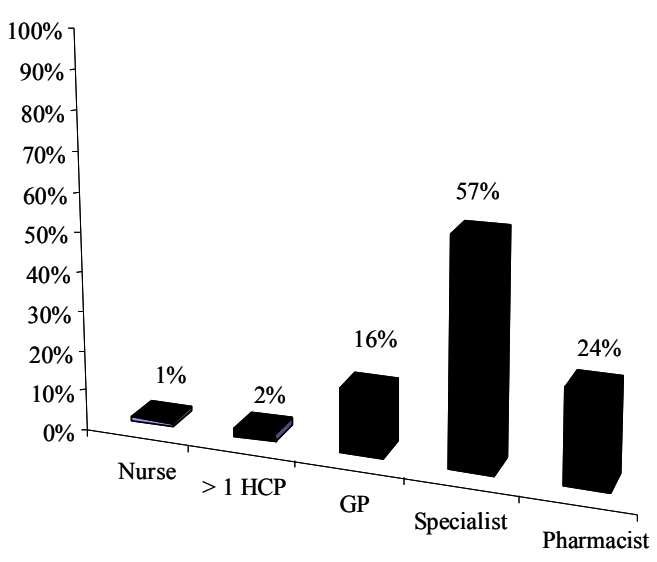

Type of health care professional

$\mathrm{GP}=$ General Practitioner

Specialist $=$ a specialist in any clinical area

$>1 \mathrm{HCP}=$ More than one health care professional

Figure 2: Proportion of health care professionals whom patients visited most; $\mathbf{A}=$ Western $A$ mman $(n=1000)$, and $\mathbf{B}=$ Eastern Amman $(n=1000)$

The second part of the questionnaire evaluated patients' responses to specific questions regarding their expectation of the role of the community pharmacist in Amman. The majority of patients believed that community pharmacists should be responsible for the sales of over-thecounter (OTC) medications without reference to another HCP (WA $73.4 \%$ vs EA $78.7 \%, p=$ 0.017 ). The others either disagreed (WA $21.8 \%$,
EA $18.0 \%$ ) or were not sure (WA $4.8 \%$ vs. EA $3.3 \%$ ). The results also show that a majority of patients believed that the role of the pharmacist with regard to prescription medications is to dispense them once there is a prescription (WA $72.2 \%$ vs EA $65.9 \%, p=0.016$ ).

A majority of patients considered provision brief counseling (up to $2 \mathrm{~min}$ ) as one of the roles of 
the community pharmacist (Figure 3). Furthermore, over half of the patients believed that pharmacists need to provide even longer counseling sessions (> $2 \mathrm{~min}$, Figure 3 \}. When it came to paying the pharmacist for additional counseling services, only a small proportion of patients from both WA and EA agreed. No significant difference was found between WA and EA.

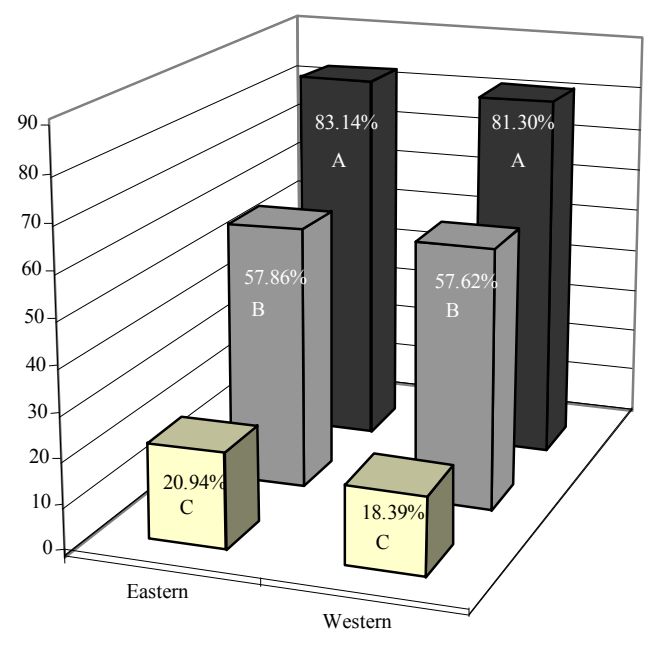

Area within Amman

Figure 3: Proportion of patients from Western and Eastern Amman (each $n=1000$ ) who agreed with having brief (up to $2 \mathrm{~min}$ ) counseling $(\mathrm{A})$ ), longer ( $>2$ min) more detailed counseling (B), and paid medication management review (MMR) services (C).

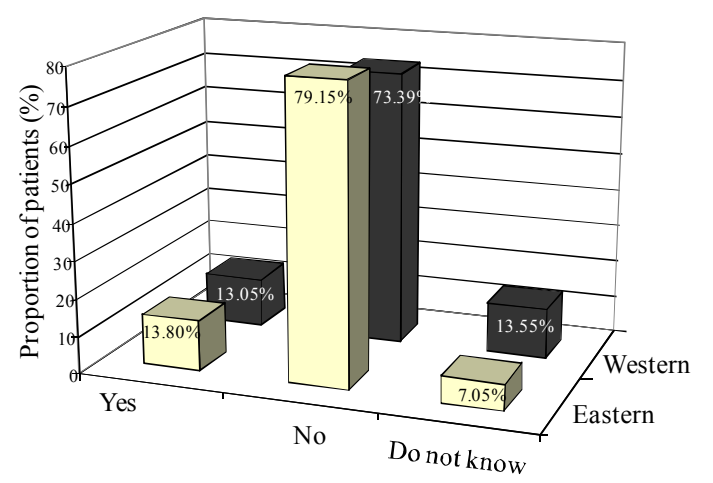

Figure 4: Proportion of patients from Western and Eastern Amman (each $\mathrm{n}=1000$ ) who agreed, disagreed or 'did not know' that their medications can be delivered to their homes and without pharmacist counseling

With regards to providing private counseling areas in pharmacies, a significantly higher proportion of patients from EA $(54.4 \%)$ than from WA $(40.3 \%)$ were in favour $(p<0.001)$. A few patients (12.2\%) from both districts of Amman were undecided on the need for a designated counseling area.

A majority of patients from both WA and EA (73.4 and $79.2 \%$, respectively, $p=0.86$ ), believed that pharmacists should refer them back to the clinical specialist when necessary (i.e., when they were not sure about their treatment) rather than prescribe medicines independently. However, only a few patients (from both WA $(13.1 \%)$ and EA $(13.8 \%)$ ) agreed that they could receive their medications from the pharmacist without any counseling (Figure 4). The proportion was significantly lower for WA than EA patients $(p<0.001)$.

\section{DISCUSSION}

There is growing interest in the roles expected of a pharmacist. Understanding these roles in the community setting and whether they meet the needs of the patient has become imperative. This study derives from the fact that in Jordan, community pharmacies are the most accessible primary health care facilities [10] In addition, this is the first study in Jordan to assess differences in patient perspective of the role of the community pharmacist based on differences in socioeconomic background.

A majority of the Jordanian patients consider the community pharmacist the major contributor to advice on the use of medications and medical devices. Similar results were reported in a study conducted in Qatar, where over $90 \%$ of respondents agreed that the community pharmacist is the primary source of information on directions on medication use [6]. The fact that the margin by which the pharmacist is favoured over the clinical specialist for this advice in EA was about twice that for WA is due, at least in part, to socioeconomic factors. The cost of a visit to clinical specialist is about US\$40 and the average monthly income for a worker in Amman is US\$500. Therefore, a direct visit to the community pharmacist is a significant saving.

Although the role of the pharmacist in counseling on medication use is positive in this regard, it can be improved further. Previous studies conducted in Jordan highlighted the fact that many patients $(23-40 \%)$ self medicate, with half of these patients purchasing their medications at community pharmacies without approaching the pharmacist for advice or counseling [7-9].

The fact that greater dependence on the pharmacist was seen in the EA for review of treatment for chronic conditions is also likely to be, at least in part, a socioeconomic effect. These findings suggest that pharmacists in lower socioeconomic areas have a greater responsibility in meeting the needs of patients who have chronic conditions. These results are in agreement with those of a study conducted in 
Canada where it was observed that clinical specialist services were comparatively underutilized by people living in areas of lower socioeconomical circumstances [10]. The fact that in our study pharmacists were preferred over GPs for review of treatment for chronic conditions in both districts of Amman further supports the positive attitude towards the role of the community pharmacist in Amman.

The choice of specialists over pharmacists when it came to trust in requesting advice on medical conditions was less apparent in EA than WA. This, again, is an opportunity for pharmacists in EA.

Although a majority of patients considered complementary treatment safer than traditional medications, patients still greatly made use of traditional medical treatments and therapeutic services. This shows that regardless of the perceived safety of complementary treatments by Jordanian patients, their use are largely 'complementary' after all. The finding that herbalists have a major role in advising patients on the use of complimentary medicine highlights a potential problem. A previous study in Amman showed that most herbalists in the area are not educated enough, and several odd and unprecedented recommendations are given to patients [5]. This indicates that educating both herbalists and pharmacists on the correct use of herbs and complementary treatments in Jordan is very important [11], and that proper regulations and licensing are needed. In this regard, WHO guidelines would be a good basis for such regulations [12].

The present study showed that there was correct awareness of the responsibilities of community pharmacists with regard to their role when it came to OTCs and prescription medications. Most respondents stated that the community pharmacist should be responsible for the sale of OTC medications based on his/her decision, while the majority also said that prescription medications should be dispensed by the pharmacist only after a prescription is presented by the patient.

The importance of patient counseling by the pharmacist cannot be overstressed [13]. Our study indicates that patients in Amman, regardless of socioeconomic status, acknowledged the importance of counseling. Yet, the drop in the proportion of patients who acknowledged the need for longer counseling indicates that the counseling role of the pharmacist should be given greater attention in the undergraduate pharmacy curriculum, via
HCPs' continuous educational programs, and wellbeing awareness programs.

A majority of respondents, regardless of their socioeconomic background, did not welcome paid pharmaceutical care services, due probably to their unwillingness to pay additional costs to the community pharmacist and their lack of awareness of the benefits of such services to their health status. There is a growing awareness of the importance of having a private counseling area in the pharmacy [14]. Lacking private counseling areas in the pharmacy is considered a barrier that hinders pharmacists from fulfilling their role fully [15]. Yet, in the current study, a considerable proportion of patients either did not agree with or were not sure of the need for these areas. These results indicate that enlightening both pharmacists and patients on the importance of a private counseling area is vital.

The fact that a majority of patients do not want medications delivered to their homes may be positive in that they want more than just their medications from the pharmacist. Having a significantly lower proportion of WA patients disagreeing with the idea may be due to previous exposure of the patients in this district to such services, and hence familiarity with it.

There are several points of strength in this study. First, the sample size (2000 patients, 1000 from each district of Amman) is very good compared with previous similar studies conducted in Jordan ( $n=1650)$ [16] and other countries around the world ( $n=100$ to 600$)[17,18]$. This large sample size promotes the generalizability of the findings of this study.

\section{Limitations of the study}

A limitation of this study is that patients are likely to have responded to the questionnaire without distinguishing between the community pharmacist and the pharmacy technician with whom the majority of the patient deal with in Amman. Pharmacy technicians only receive a middle level professional education and are licensed to dispense prescription drugs under the supervision of the pharmacist. We, however, tried to minimize this issue during the study by stating the difference between the two categories of personnel to the patient at the time of completing the questionnaire.

\section{CONCLUSION}

The results of this observational study are important for future social pharmacy studies since they reveal a clear socioeconomic 
influence on patient perspective of the role of the community pharmacist relative to those of other HCPs. The study reveals a greater appreciation of the pharmacist's role among people of lower socioeconomic status. Furthermore, our findings indicate a positive patient perception of the roles of the community pharmacist in Amman and that these roles can be further enhanced for the benefit of patients.

\section{ACKNOWLEDGMENT}

This study was supported by a grant (no. 2009/6) from Applied Sciences University, Amman, Jordan. The authors wish to thank Pharmacist Mohammad Gabayen for his help with data entry and analysis, and also to all the pharmacy students who helped with the data collection phase of this study.

\section{REFERENCES}

1. Basheti IA, Armour CL, Bosnic-Anticevich SZ, Reddel HK. Evaluation of a novel educational strategy, including inhaler-based reminder labels, to improve asthma inhaler technique. Patient Educ Counsell 2008; 72 (1): 26-33.

2. Currie JD, Doucette WR, Kuhle J, Sobotka J, Miller WA, McDonough RP, Tice AL. Identification of essential elements in the documentation of pharmacistprovided care. J Am Pharm Assoc 2003; 43 (1): 41 47.

3. Farris $K B$, Fernandez-Llimos $F$, Benrimoj $S I$. Pharmaceutical care in community pharmacies: practice and research from around the world. Ann Pharmacother 2005; 39 (9): 1539-1541.

4. Hepler CD, Strand LM. Opportunities and responsibilities in pharmaceutical care. Am J Hosp Pharm 1990; 47 (3): 533-543

5. Abu-Irmaileh BE, Afifi FU. Herbal medicine in Jordan with special emphasis on commonly used herbs. J Ethnopharmacol 2003; 89 (2-3): 193-197.

6. Internet World States. Found at http://www.internet worldstats.com/. Accessed 15th of May 2012.

7. El Hajj MS, Salem S, Mansoor H. Public's attitudes towards community pharmacy in Qatar: a pilot study. Patient Prefer Adherence 2011; 5 405-422.
8. Otoom S BA, Hadidi H, Hasan M, Al-Saudi K. Evaluation of drug use in Jordan using WHO prescribing indicators. East Mediterr Health J 2002; 8 (4-5): 544-549.

9. Al-Bakri AG, Bustanji Y, Yousef AM. Community consumption of antibacterial drugs within the Jordanian population: sources, patterns and appropriateness. Int J Antimicrob Agents 2005; 26 (5): 389-395.

10. Yousef AM, Al-Bakri AG, Bustanji Y, Wazaify M. Selfmedication patterns in Amman, Jordan. Pharm World Sci 2008; 30 (1): 24-30.

11. Veugelers $P J$, Yip AM. Socioeconomic disparities in health care use: Does universal coverage reduce inequalities in health? J Epidemiol Community Health 2003; 57 (6): 424-428.

12. Jeschke E, Ostermann $T$, Luke $C$, Tabali $M$, Kroz $M$, Bockelbrink A, Witt CM, Willich SN, Matthes $H$. Remedies containing Asteraceae extracts: a prospective observational study of prescribing patterns and adverse drug reactions in German primary care. Drug Saf 2009; 32 (8): 691-706.

13. WHO Report on the Intercountry Meeting on the Development of Guidelines for National Policy on Traditional Medicine. 21-23 December, EMRO, Alexandria, Egypt.

14. Basheti IA, Armour CL, Reddel HK, Bosnic-Anticevich SZ. Long-term maintenance of pharmacists' inhaler technique demonstration skills. Am J Pharm Educ 2009; 73 (2): 32.

15. McDermott JH, Christensen DB. Provision of pharmaceutical care services in North Carolina: a 1999 survey. J Am Pharm Assoc 2002; 42 (1): 2635.

16. Odedina FT, Hepler $C D$, Segal $R$, Miller $D$. The Pharmacists' Implementation of Pharmaceutical Care (PIPC) model. Pharm Res 1997; 14 (2): 135144.

17. Daoud A, Al-Safi S, Otoom S, Wahba L, Alkofahi A. Public knowledge and attitudes towards epilepsy in Jordan. Seizure 2007; 16 (6): 521-526.

18. Costa FP, Duggan C, van Mil JW. Assessing the pharmaceutical care needs of asthmatic patients. Pharm World Sci 2004; 26 (6): 313-318.

19. Montero A, Feal B, Calvin M, Margusino L, Hurtado JL, Vazquez I, Martinez A, Jorge S, Martin I. Quality perceived by outpatients at the pharmaceutical care clinic. Farm Hosp 2006; 30 (2): 105-111 